\title{
Letter to the editor: Translation, cross-cultural adaptation, and validation of the Italian version of the Oxford Shoulder Instability Score
}

\author{
Fatih Özden ${ }^{1}$ \\ Received: 29 September 2019 / Accepted: 9 October 2019 / Published online: 12 November 2019 \\ (C) SICOT aisbl 2019
}

I read the article with great interest by Mazzoni et al. entitled "Letter to the editor: Translation, cross-cultural adaptation, and validation of the Italian version of the Oxford Shoulder Instability Score" and would like to address some possible mistakes and raise some questions about methodological and technical issues which may affect the results of the study [1].

Firstly, the authors stated that they used the "translation-back translation" procedures recommended by Beaton and colleagues for the Italian translation and cultural adaptation of the scale and conducted a pre-test on 15 healthy cases to confirm the comprehensibility of the Italian version. However, as can be seen from the reference, Beaton et al. suggest that this "pre-test" should be performed with at least 30-40 cases [2].

The study was carried out with 25 cases $84 \%$ of whom were re-test ( 21 cases). It was stated in the "discussions" section that the sample size was determined by considering the studies that have different methodologies which conducted for different surveys. Even if we ignore this inconsistency, the question I want to ask the authors is this: which parameter (standard deviation etc.) did you use from these studies to determine the sample size? The sample size recommended, in comparison with studies by Altman, requires at least 50 data usage [3]. Also, the number of patients is low for the validity and reliability of this questionnaire, considering the recommendation that the sample size should be ten times the number of items [4].

Fatih Özden

fatihozden@mu.edu.tr

1 Köyceğiz Vocational School of Health Services, Elderly Care Department, Muğla Sttkı Koçman University, Muğla, 48800 Köyceğiz, Turkey
In the "Statistical analysis" section, the authors of the study stated that "Cronbach's alpha was calculated to check for internal consistency of the subscales and total scale." But it is seen that there was no analysis of the subscales. Using SF-12 subscores in the validity analysis and presenting the negative or positive correlations could increase the sophistication of the validity results.

It was stated that cultural adaptation was made, but the demographic information about the cultural level of the cases was not recorded or presented. Knowledge of the cultural level of cases is important to describe this adaptation. It would be more appropriate to carry out this study in which cultural adaptation was carried out with a multicenter study with different cultural characteristics from different segments.

Last but not least, in the "Discussions" section, it is seen that there was no comparison with the validation results of the other-version studies, especially in terms of the methodology and results comparison.

\section{References}

1. Mazzoni B, Cucchi D, Giovannelli T, Paci M, Arrigoni P, Nicoletti S (2019) Translation, cross-cultural adaptation, and validation of the Italian version of the Oxford Shoulder Instability Score. International orthopaedics 43(9):2125-2129

2. Beaton DE, Bombardier C, Guillemin F, Ferraz MB (2000) Guidelines for the process of cross-cultural adaptation of selfreport measures. Spine 25(24):3186-3191

3. Altman DG (1990) Practical statistics for medical research. CRC press

4. Tabachnick BG, Fidell LS, Ullman JB (2007) Using multivariate statistics, vol 5. Pearson Boston, MA

Publisher's note Springer Nature remains neutral with regard to jurisdictional claims in published maps and institutional affiliations. 